\#139 Análise microscópica da superfície de esmalte após remineralização de lesões de cárie

C. Salvado*, C. Ascenso, J. Carmo, A. Peixoto, P. Carvalho, A.G. Manso.

CiiEM - Centro de Investigação Interdisciplinar Egas Moniz, Quinta da Granja, Portugal, CeFEMA, Instituto Superior Técnico, Universidade de Lisboa and SINTEF Materials and Chemistry, Oslo

Objetivos: Analisar e comparar microscopicamente a superfície do esmalte humano, após remineralização de lesões iniciais de cárie dentária através de distintos agentes remineralizadores.

Materiais e métodos: 8 espécimenes foram obtidos a partir de 2 molares humanos e aleatoriamente distribuídos em 4 grupos $(\mathrm{n}=8) .3$ Grupos (A-C) foram submetidos a solução tampão de ácido lático a pH 5, durante 6 dias para indução de lesão de cárie. Posteriormente foram escovados duas vezes ao dia, com escova elétrica e pasta dentífrica fluoretada (1450ppm de fluoreto de sódio) (ColgateTM, Triple Action), durante 7 dias. No Grupo B ( $\mathrm{n}=2)$ adicionou-se verniz de flúor de alta concentração com fosfato de cálcio (<5\%) (ClinproTM White Varnish, 3M) uma vez por semana. No Grupo C ( $\mathrm{n}=2)$ adicionou-se caseína fosfopeptídea com fosfato de cálcio amorfo (GC Tooth Mousse, RecaldentTM) uma vez por dia. O Grupo D ( $n=2)$ constituiu o grupo controlo, não foi induzida lesão de cárie nem tratamento remineralizador. Todos os espécimenes foram armazenados em saliva artificial durante todo o estudo. A superfície de cada espécime foi analisada com microscópio eletrónico de varrimento (JEOL JSM-700001F).

Resultados: No Grupo A observa-se rugosidade e desorganização da superfície com um aspeto lacunar e heterógeneo e dispersão na orientação dos prismas; no Grupo B a superfície é mais regular, evidenciando-se uma maior oclusão interprismática pelo preenchimento parcial das lacunas com depósitos de fosfato de cálcio, no entanto, apresenta alguma desorientação dos prismas; no Grupo $C$ a superfície é mais homogénea com maior preenchimento das lacunas pela maior deposição mineral; no Grupo D evidencia-se a microrugosidade natural da superfície do esmalte.

Conclusões: A aplicação única de pasta dentífrica fluoretada (Grupo A) e a sua combinação com um verniz de flúor de alta concentração com fosfato de cálcio (Grupo B) e com caseína fosfopeptídea com fosfato de cálcio amorfo (Grupo C), produzem imagens compatíveis com a remineralização do esmalte. A combinação de pasta fluoretada com caseína fosfopeptídea com fosfato de cálcio amorfo é a que produz uma melhor avaliação na qualidade de superfície de esmalte. http://doi.org/10.24873/j.rpemd.2017.12.161

\#140 Influência dos protetores bucais na capacidade aeróbia de atletas com aparelho ortodôntico

Ana Carolina Rodrigues, Ana Martins Corte-Real, Francisco Caramelo, Sónia Alves*

Faculdade de Medicina da Universidade de Coimbra

Objetivos: A prática desportiva está frequentemente associada à ocorrência de trauma oro-facial. O principal objetivo deste trabalho foi avaliar a influência dos protetores bucais na capacidade aeróbia de atletas Sub-18 portadores de aparelho ortodôntico fixo utilizando o teste de Luc-Léger. Como objetivos secundários, pretendeu-se avaliar o conhecimento dos atletas sobre estes dispositivos e perceber possíveis dificuldades com a sua utilização.

Materiais e métodos: De um total de cento e trinta e nove atletas convocados para o presente estudo, participaram na primeira fase setenta e três. Dentro desta amostra, a totalidade do estudo contou com sessenta atletas de clubes de rugby e basquetebol locais. Avaliou-se o conhecimento sobre protetores bucais no desporto através de um questionário inicial. Os atletas foram distribuídos em dois grupos, experimental e controlo, consoante apresentassem ou não aparelho ortodôntico fixo, respetivamente. A análise da capacidade aeróbia foi feita através da comparação entre os valores de consumo máximo de oxigénio resultantes do teste de Luc-Léger duas vezes, com e sem protetor bucal em boca. Foi realizado um segundo questionário utilizando a escala analógica visual para avaliar a aceitação e possíveis dificuldades sentidas com a utilização do protetor por parte dos atletas durante o exercício de corrida de 20 metros. Foram utilizadas técnicas descritivas e testes estatísticos para avaliação das possíveis diferenças entre grupos.

Resultados: A utilização de protetores bucais individualizados não influencia a capacidade aeróbia de atletas com ou sem aparelho ortodôntico fixo. 23.3\% referem utilizar protetores durante a atividade física, como treino e/ou competição, sendo o tipo 'boil and bite' mencionado como preferido. Dos oito parâmetros avaliados no segundo questionário, o valor atribuído ao protetor como mais aceitável foi o correspondente à estabilidade. A interferência do protetor com a comunicação foi a mais referida, apresentando o menor valor de atribuição na escala.

Conclusões: Não existem diferenças na capacidade aeróbia de atletas sub-18 com e sem aparelho ortodôntico fixo durante o uso de protetores bucais individualizados. Devem desenvolver-se estratégias para consciencializar jogadores, treinadores, pais e a restante comunidade para riscos que envolvem a elevada prevalência de trauma oral em desportos de contacto. Os médicos dentistas também deverão promover recomendações sobre o melhor tipo de proteção a usar de forma a diminuir a ocorrência de lesões deste tipo. http://doi.org/10.24873/j.rpemd.2017.12.162

\section{\#141 Prevalência de traumatismos dentários e uso de protetor bucal durante o exercício militar 4 CrossMark}

Luís Pedro Pereira Azevedo*, David Miguel Simões e Martins, Nélio Veiga, André Correia

Instituto de Ciências da Saúde - Viseu, Universidade Católica Portuguesa

Objetivos: Determinar a prevalência de traumatismos orais durante o exercício militar; Avaliar o conhecimento dos militares sobre a atitude a tomar perante a ocorrência de um traumatismo oro facial; Quantificar o uso de protetor bucal durante o exercício. 
Materiais e métodos: Estudo observacional transversal. Amostra composta por 122 militares de um total de 408 do Regimento de Infantaria n. ${ }^{\circ} 14$ - Viseu, obtendo uma percentagem de participação de $29,9 \%$. A recolha de dados foi efetuada através de um questionário com questões referentes à ocorrência de traumatismos dentários durante a prática de exercício físico militar, à influência da saúde oral no rendimento físico, à atitude a tomar e onde se dirigir perante a ocorrência de um traumatismo dentário e à prevalência de uso de protetor bucal.

Resultados: A amostra final é reduzida face ao número de militares existentes no Regimento, visto que muitos se encontravam em missões fora do país ou estavam destacados para algumas tarefas fora do Regimento. Na amostra estudada, em que dos 122 militares, 95,9\% são do género masculino, a média de idades foi de $25,83 \pm 7,49$. Cerca de $11 \%$ dos militares refere que um problema de saúde oral já prejudicou o seu desempenho físico num treino ou numa missão militar. Verificou-se que $56,6 \%$ tem uma frequência de até 5 treinos físicos militares por semana, sendo que $41,8 \%$ treina entre 10 e 20 horas por semana. Na amostra estudada, 5,7\% já sofreu uma lesão dentária durante a prática de exercício físico militar, sendo que 3,3\% diz respeito a fraturas dentárias e 2,5\% a avulsões. Dos militares que sofreram uma lesão dentária, apenas 28,6\% visitou o médico dentista após a lesão, sendo que somente $20 \%$ visitou no mesmo dia. Verificou-se ainda que 21,3\% da amostra estudada já observou uma lesão dentária num colega durante o exercício militar. Concluiu-se também que 32,8\% se dirigia ao hospital no caso de perda de um dente. Relativamente às atitudes a tomar no caso de avulsão, 54,9\% não sabe como deve agir. Por fim, apenas 7,4\% usa protetor bucal. Dos que não usam, 31,1\% não sabe o que é e 53,3\% não acha necessário a sua utilização.

Conclusões: Os militares, como praticantes de exercício físico em alta intensidade, são um grupo em que a existência de traumatismos orais durante o serviço militar é comum e pode ser prevenida com o uso de protetores bucais adequados. É necessário também, face aos resultados obtidos, uma melhor instrução sobre as corretas medidas a tomar perante a ocorrência de um traumatismo.

http://doi.org/10.24873/j.rpemd.2017.12.163

\#142 Caracterização dos comportamentos de saúde oral numa amostra de militares portugueses

Nélio Veiga*, Luís Pedro Pereira Azevedo, David Miguel Simões e Martins, André Correia

Instituto de Ciências da Saúde - Viseu, Universidade Católica Portuguesa

Objetivos: Caracterizar os comportamentos de saúde oral de uma amostra de militares portugueses do Regimento Infantaria $n .^{\circ} 14$ - Viseu.

Materiais e métodos: Foi realizado um estudo observacional transversal onde avaliámos 122 militares (117 Homens e 5 Mulheres) de um total de 408 militares do Regimento de Infantaria n. ${ }^{\circ} 14$ - Viseu, obtendo uma percentagem de participação de $29,9 \%$, visto que muitos se encontravam em missões fora do país ou estavam destacados para algumas tarefas fora do Regimento. A recolha de dados foi efetuada através de um questionário com questões referentes a aspetos sócio-demográficos e comportamentos de saúde oral e respondido pelos militares disponíveis.

Resultados: Na amostra estudada, a média de idades foi de $25,83 \pm 7,49$. Cerca de $45,9 \%$ dos militares são fumadores. Verificou-se que $34,4 \%$ dos militares estudados não escovam os dentes pelo menos duas vezes por dia e 5,7\% nunca escova os dentes a seguir às refeições. Relativamente à higiene oral, a grande maioria dos militares $(96,7 \%)$ usa escova dentária, no entanto, apenas 18\% utiliza fita dentária, 35,2\% utiliza algum tipo de colutório, 4,9\% utiliza escovilhão interdentário e 8,2\% usa escova de língua. No que diz respeito à pasta de dentes fluoretada, 64,8\% utiliza, no entanto, 22,1\% não sabe se usa pasta de dentes com flúor. Por fim, relativamente às visitas regulares ao médico dentista, $12,3 \%$ já não visita o médico dentista há mais de 2 anos, 27\% afirma que só visita o médico dentista em caso de dor e $19,7 \%$ refere o preço da consulta como o principal motivo de não visitar mais frequentemente.

Conclusões: Os comportamentos de saúde oral na amostra estudada revelam a necessidade de melhor instrução e aumento de índices de motivação para os bons hábitos de higiene oral.

http://doi.org/10.24873/j.rpemd.2017.12.164

\#144 Excesso de Peso e Obesidade na Infância: preditor de risco para cárie dentária

Maria Júlia Rodrigues*, Augusta Silveira, Raquel Silva, Maria Conceição Manso, Teresa Sequeira

Universidade Fernando Pessoa

Objetivos: Avaliar a relação entre o excesso de peso/obesidade e a prevalência de cárie dentária em crianças com idade escolar. Identificar preditores de risco para desenvolvimento de cárie dentária na infância.

Materiais e métodos: Este trabalho de investigação foi aprovado pela Comissão de Ética e Agrupamento de Escolas. Avaliaram-se 40 crianças (6-9 anos). Registou-se a composição dos lanches escolares. Foi realizada uma avaliação oral (índice cpod/CPOD, índice significativo de cárie (SIC), prevalência de cárie dentária, índice de tratamentos restauradores, índice de higiene oral simplificado e observação dos dispositivos de higiene oral de cada criança). Complementou-se com uma avaliação do perfil antropométrico de cada participante (determinação do Índice de Massa Corporal-pesagem e medição da estatura), classificando em 3 categorias: peso normal, excesso de peso e obesidade. A identificação de fatores univariados/ multivariados de risco ou proteção associados ao resultado cárie dentária $(\mathrm{CPO}>0)$ na população, foi pesquisada através de regressão logística (odds ratio e respetivos intervalos de confiança a 95\%), conjugado com a informação resultante de testes de Qui quadrado/Exatos de Fisher.

Resultados: Quanto à avaliação do perfil antropométrico verificou-se que $55 \%$ dos participantes no estudo têm um peso adequado à sua idade e estatura, $17,5 \%$ têm excesso de peso e $27,5 \%$ estão em situação de obesidade. Nos indivíduos obesos 